\title{
Linking Citizenship, Participation and Accountability: A Perspective from PRIA
}

Rajesh Tandon*

Exclusion of the poor and the marginalised from the development process has given rise to the concerns for active citizenship, responsible participation of people and accountability in the development process. Such concerns seek alternate forms of development, which foster more inclusive and deliberative forms of citizen engagement. The Development Research Centre (DRC) on Citizenship, Participation and Accountability aims to re-cast such concerns on inclusion, participation and accountability in a rights-based and citizenship-centered mould both in theory and practice.

With this agenda, there is a greater recognition that development initiatives should more adequately consider the complexity and diversity of poverty, be built from the "bottom up' rather than from the top-down, and respond to the praxis of social equity and justice. There is also a greater recognition that participatory decentralization and democratization are key to development initiatives. New forms of decentralization and local governance potentially offer new spaces for citizen voice and the construction of new forms of citizenship. With the concerns about good governance and state responsiveness have also come issues about the capacity of citizens to engage and make demands on the state. Participatory citizenship calls for the development of awareness and knowledge of rights of citizenship. A conceptual elaboration of the themes of citizenship, participation and accountability in a human rights perspective will facilitate the understanding of the potential of new spaces for citizen voice and the strengthening of citizen voice.

For the last twenty years, the Society for Participatory Research in Asia (PRIA) - a non-profit, international centre for learning and promotion of participation and democratic governance based in New Delhi, India - has been promoting people centered development initiatives within the perspective of participatory research at a local, national, regional as well as a global level. PRIA's vision of a desirable world is one where relations across individuals, families, communities and nations are characterized by values of equity, justice, freedom, peace and solidarity. It believes in creating a balance between economic and social development; it focuses on ecological

\footnotetext{
* A version on this article was previously published in PRIA's publication, Innovations in Civil Society, Volume 1, Number 1, July 2001 and is based on a presentation given by Rajesh Tandon at the inception workshop of the Development Research Centre on Citizenship, Participation and Accountability, 22-24 November, 2000.
} 
regeneration based on local priorities. We seek a world where citizens' rights and responsibilities are carefully nurtured through a balance between authority and accountability, and where individual freedom is sustained with collective solidarity for public welfare/well-being.

At the core of PRIA's work has been the promotion of participation and empowerment of the poor, the oppressed, women, dalits (lowest castes) and tribals. At times, PRIA has worked directly with these groups and at times has also carried out interventions through intermediary organisations. Building on the premise that "knowledge is power" PRIA aims to strengthen popular knowledge, demystify dominant concepts and promote experiential learning and people's participation.

Empowerment for PRIA involves the twin processes of learning and organising, linking the efforts and challenges of promoting people's participation and democratic governance through local grassroots action with a systematic documentation of the processes involved. PRIA's work has spanned micro-action in local settings at the grass-roots level to national and international initiatives on the same issues, which arise organically in response to emerging opportunities and trends.

PRIA's intervention on facilitating participation of the poor and the marginalised is influenced by some key approaches to participation, which have grown both from our conceptual understanding as well as from our practical experiences of participatory action research. In the article below, I will share some of these key conceptual lessons, as well as describe some research projects which we are now developing in conjunction with the Development Research Centre on Citizenship, Participation and Accountability which we hope will develop our learning further.

\section{The importance of the historical approach to the spaces for participation}

An historical approach to participation implies looking at forms of participation both in the traditional and modern context. In India, both of these forms of participation coexist. There have been, and continue to be, traditional forms of participatory mechanisms in the caste, village or tribal indigenous communities. These are often voluntary, self-help informal initiatives of people arising out of their needs, characterized by a recognition of their dependency on each other. The people's traditional groups are largely independent of any kind of external inducement. They provide space for citizens to articulate their demands, to negotiate and to influence decisions which affect their lives. They also play an important role in their struggles for justice and a good life and facilitate the organization of community and collective action. 
Traditional spaces for participation increasingly sit side-by side, with other externally created spaces. Development projects of a large-scale nature under the aegis of Government and bilateral and multi-lateral agency programmes have, of late, led to the creation of a number of village level development committees, which are primarily sectoral, and project-based. In addition, the 73rd Constitutional Amendment Act in 1993, by constitutionalizing the Panchayati Raj Institutions (PRIs) as a third tier of governance and the Panchayats as the local elected grassroots level governing body, has provided yet further opportunities for people's participation in local development. The modern forms of organization like village education committees $\alpha$ watershed committees, and the modern forms of local elected bodies are characterized by formalized relationships. These organizations are often externally induced and guided to meet predetermined objectives. In India, both forms of participation simultaneously exist: the traditional village forms work alongside the project or sector based development committees and the elected bodies.

At the local level, then, there is a multiplicity of potential spaces for participation. In a current research project related to the DRC on Citizenship, Participation and Accountability, PRIA is exploring further the linkages, conflicts and dynamics between these traditional, development and statutory decentralised local bodies in forestry and watershed management projects. These institutional mechanisms are working in a village community simultaneously with overlapping jurisdiction. All claim to shape and determine community involvement on various issues at the grassroots level. While the dynamics of participation, and even the identities claimed by citizens in these multiple spaces may vary, it is often the same individuals within the village who are involved in the same institutional structures, each set up to ensure people's participation in their separate programmes.

At the same time, such multiple forms and sites of participation challenge the myth of the homogeneity of community, as the interests of members may vary within and between each type of institutions. In each space, contests over whose knowledge and whose voice are legitimate will affect who participates and with what outcomes. Moreover, the separation of participatory forest management and participatory watershed management agendas through multiple committees may create dangerous complacency by diverting from the cross-cutting issues related to local networks of power and resource use. Consequently, they run the risk of degenerating into merely another way of co-opting the excluded and the marginalised citizen into the agendas of powerful.

Through studying and engaging in the dynamics of participation at the local level, it becomes clear that it is a fallacy to assume that the 'subaltern' consist of a simple and homogeneous group of the poor, and have-nots. On the contrary, they are a highly stratified group. Taking the issues of control and ownership as point of departure, we 
find that differences exist within each stratum of the subaltern. The differences are profound and extremely complex within categories of caste, class, gender and ethnicity. By overlooking the in-built dominant relations of power and production within the social system, we undervalue the situation of shrinking spaces and options of various categories of subaltern. A more nuanced subaltern view will take into consideration the columns and rows of participation between different strata. The various potential spaces for participation are in fact shaped by different vertical and horizontal formations and relationships.

\section{Political and Cultural Meanings of Participation and Citizenship}

Historically, much of the work on participation has been on its political meaning, which has been inevitably linked to people's relationship with the state. People are defined either as beneficiaries or as voters. They are either beneficiaries of the government largess or patronage or development programme, which means 'you sleep, and the state delivers', or mere voters, which means periodically 'you exercise your vote and then forget about it until the next election'.

Citizens in India, as perhaps elsewhere, are becoming mistrustful of public institutions and government agencies. They are becoming apathetic towards governance and dependent on the state for their welfare. This is one of the things that we discovered in the 'Citizens and Governance' study conducted for the Commonwealth Foundation (1999). This report is based on the answers given by thousands of ordinary citizens, citizen leaders and citizens in influential positions in 47 Commonwealth countries, to a series of questions about the kind of society they want future generations to live in, and the role of government and citizens in creating it. There was a clear demand in citizen's voices that they be treated neither as beneficiaries of government program and schemes, nor as voters occasionally electing their representatives - but as active citizens who participate both in public arenas as well in their own associations and communities.

Our study further revealed that people did not perceive themselves as citizens in the normal political sense, that is in a state-citizen relationship. The growing alienation from the state has resulted in increasing marginalisation of a large section of people who have been denied access to political institutions and their own traditional structures of community and habitation. For instance, a group of immigrants from Kerala, who went to Gulf for employment, felt they did not belong when they returned to India. The classic situation was the Gulf war in 1991, when the state abandoned these people. Politically, they neither belonged to Kuwait nor did they belong to India. But they saw themselves as citizens in the cultural context. The cultural meaning of citizenship was different from the political meaning, and is linked more to a sense of belonging and responsibility toward community, fraternity, and kinship groups rather than towards the state. 


\section{The Individual and the Collective Notion of Citizenship}

Citizens gaining voice and choice are the key challenges facing us today. The central issue is, therefore, the restructuring of the system and polity, which protects the liberties and rights of the poor and the marginalised. However, there is a need for re-thinking what we mean by the 'politicization of the participation of citizens' - not in an electoral sense but in basic sense of developing active citizenship. The conception of active citizenship must be based on an understanding of cultural diversities and multiple identities as well as on an array of alternative systems of survival and sustenance. Direct participatory democracy, to change the existing discriminatory institutions and practices throughout the society entails tolerance for the plurality of culture and of perspectives on citizens' actions.

Individual notions of citizenship, which often underlie concepts of active citizenship, are directly linked to discourses about merit, entitlement and contractual relationships. They transcend the collective identities of kinship, caste and communities, and thereby, negate some fundamental principles of communities and ascribed identities. On the other hand, kinship, caste, community, social obligations, cultural relationships and religious forms of participation, are traditionally collective in nature, and also demand forms of active participation and allegiance. In these indigenous civil societies, public service is desirable for its contribution to the advancement of the collective good. The common good is defined in a collective sense within a larger framework of common good, as opposed to one based on individual rights and gains. In our context, we are not exactly in the postmodern world, which is based on the assumption of motivating individuals to pursue self-interest vigorously. We are, in fact, somewhere in the interface between the posttraditional and pre-modern state of world. As a result, the collective nexus of the two approaches is unavoidable.

The different sets of discourse on citizenship provide conflicting forms of legitimization. At times, these contrasting discourses are interrelated, where different groups of people cooperate in their struggle for recognition and resources. Sometimes, there are tensions in the rights and obligations, as inherent in the individual notions of citizenship, with those claims and obligations that the same individuals enjoy as members of kinship, caste, community, socio-cultural and religious groups where forms of participation are collective in nature. Alternatively, the collective rights may exist in tension to each other. Different members within existing groups compete with each other for access to resources and recognition. There is a need to examine the relationship between the individual and the collective and the meaning that these have for the forms of participation and rights to participation. 
The creation of a new state of Jharkhand in the Eastern India provides an interesting opportunity to understand further the various images and meanings of rights and citizenship (and is the site for a current PRIA research project on the subject). Jharkhand is predominantly a tribal region, rich in natural resources. Yet the tribals in this region live in penury. Their history has been one of exploitation, subjugation and marginalisation. The creation of Jharkhand was the result of a long struggle by the tribals who, on the basis of their separate cultural identity and in opposition to various forms of exploitation by the non-tribals, laid claim for a separate province. Creation of the Jharkhand State in some way is an expression of their will to break loose from the exploitative past, and break new ground.

At present the key issues of concern before the tribals of Jharkhand relate to their cultural alienation, political alienation and economic alienation. The state apparatus, with its brahmanical worldview and centralized top-down approach to development in the area, has dispossessed the tribals of their livelihood, culture and religion. It is important that the new state is constructed from the bottom by utilizing the indigenous resources both human and natural. If in the changed circumstance of a new state, the new objectives like establishing self-rule autonomy, respecting traditional forms of tribal governance, and supporting eco-friendly economic enterprises and life-oriented education are not continued, then the trib als will become aliens in their own land. The tribals have got their territory "Rajya" but now they have to assert for their self-rule "Raj", which is their right.

\section{Broadening the Meaning of the Public}

As we attempt to understand the meanings of citizenship in different contexts, there is also a need to re-formulate our understanding of what is public and what is private. Common conceptualizations have resulted in a definition that equates private with what goes on within the family and public with what concerns the government. It is important to recognize that private opinions become the basis for evolving a public position and the question of privacy is a relative issue within a broader framework of a community. Similarly everything that is of public interest, everything that concerns the public arena does not automatically become a concern for the state or its agencies.

There are three issues in the meaning of public. The first one is 'public good'. We are very concerned, in our context, to explore how public good is established, and how it is contested and how any kind of broad-based consensus, even if not a permanent consensus, is reached. Frankly in our society, there is no 'public good' consensus at the moment. There are contestations on a whole range of issues, from basic education to globalization. 
The second issue is about 'public institutions'. We increasingly believe that public institutions do not only mean government institutions. We believe that they include all institutions, which operate in society in a public manner. Private sector institutions, which increasingly use public resources, civil society organizations and NGOs, are all public institutions because they operate in public space, and act on public issues.

This leads to the third issue vis a vis 'public accountability'. We are particularly interested in what we are beginning to call multi-party accountability. We are beginning to experiment with different parties holding each other accountable, as opposed to the exclusive notion that there is only one way accountability.

In our work in Maharashtra, for instance, we are using the concept of multiparty accountability to engage local communities, industry and government in promoting more just and equitable industrial development. Within the context of the industrial development process, implicit contracts exist between various actors/stakeholders in terms of rights and responsibilities that they are entitled to and expect of one another. But often these remain unarticulated. As a result, the responsibilities of the institutions towards the rights to safe and healthy living and secure livelihood for workers go unfulfilled. On the other hand, the mobilization of community participation through such efforts as participatory health and environmental monitoring can be a powerful tool for demanding accountability. This requires demystification of concepts (like environment audit, disaster management) and laws (e.g. pollution and clearance procedures, self-regulation, etc). Information, evidence and an enabling space for open and transparent public debate are powerful tool for creating a culture of accountability.

\section{Linking Citizenship, participation and accountability - the governance wheel}

It is one thing to debate the three concepts of citizenship, participation and accountability individually and approach them singly, but it may be worthwhile to think about how they fit together. We need to look at how participation assures accountability and how a sense of citizenship enables participation. I look at three of them together as a 'governance wheel'.

Participation is about the involvement of all stakeholders, the state and the non-state, through a process of communication and negotiation to influence the decisions that affect their lives. Participation leads to the creation and sustenance of accountability. A sense of the right to accountability provides the basis on which citizens can act. It leads to openness and transparency in policy making. Such accountability builds up social reciprocities characterized by equity, inter-group tolerance and inclusive citizenship. Responsible and active citizenship, in turn, results in meaningful participation. 
There is yet another reverse perspective on the synergy amongst citizenship, accountability and participation. Citizenship gives the right to hold others accountable and accountability is the process of engaging in participation. An active citizenship would assert itself by seeking greater accountability from service providers through increased dialogue and consultation, and by monitoring and assessing performance externally and mutually. The concept of citizenship encompasses the concepts of social rights, social responsibility, and social accountability. Thus, the accountability induced by an active citizenship would necessarily have a participatory dimension.

[Insert governance wheel figure here]

Either way, citizenship, participation, and accountability together form the basis of 'governance wheel', which move in an integrated, inter-linked, and synergised manner and which affect each other in a dynamic relationship. Citizenship, participation and accountability are in fact essential components of any kind of meaningful governance, not just in government institutions but in all institutions which occupy public space.

\section{References}

Commonwealth Foundation (1999), Citizens and governance: civil society in the new millenium. The Commonwealth Foundation, London.

Knight, B. Chigudu, H. and Tandon, R. (2001), Reviving Democracy: Citizens at the Heart of Governance, Earthscan, London. 